Research Article

\title{
Experimental Optimization of Annular Polishing Parameters for Silicon Carbide
}

\author{
Yuan Liu, ${ }^{1}$ La Han, ${ }^{2}$ Haiying Liu, ${ }^{3}$ Yikai Shi, ${ }^{4}$ and Junjie Zhang $\mathbb{D}^{2}$ \\ ${ }^{1}$ School of Astronautics, Harbin Institute of Technology, Harbin 150001, China \\ ${ }^{2}$ Center for Precision Engineering, Harbin Institute of Technology, Harbin 150001, China \\ ${ }^{3}$ Xiaguang Optical Electron Co., Ltd, Yangzhou 225127, China \\ ${ }^{4}$ Science and Technology on Integrated Logistics Support Laboratory, National University of Defense Technology, \\ Changsha 410073, China
}

Correspondence should be addressed to Junjie Zhang; zhjj505@gmail.com

Received 22 June 2018; Revised 3 August 2018; Accepted 27 August 2018; Published 25 September 2018

Academic Editor: Fernando Lusquiños

Copyright (c) 2018 Yuan Liu et al. This is an open access article distributed under the Creative Commons Attribution License, which permits unrestricted use, distribution, and reproduction in any medium, provided the original work is properly cited.

Machined surface quality has a strong impact on the functionality of silicon carbide-based components and devices. In the present work, we first analytically investigate the complex coupling of motions in annular polishing based on the Preston equation, which derives the influential parameters for material removal. Subsequently, we conduct systematic annular polishing experiments of reaction-bonded silicon carbide to investigate the influence of derived parameters on polished surface quality, which yield optimized polishing parameters for achieving ultralow surface roughness of reaction-bonded silicon carbide.

\section{Introduction}

Reaction-bonded $(\mathrm{RB})$ silicon carbide $(\mathrm{SiC})$ is one of the preferred materials for manufacturing optical mirrors due to its unique characteristics of low density, high strength, low thermal expansion, high thermal conductivity, and high chemical inertness [1]. Machined surface quality plays an important role in determining the functionality of SiC-based components and devices. For instance, according to the theory of total integral scattering (TIS), the surface scattering capability of optical mirror is closely related to its surface roughness, as the TIS increases sharply with the increase of surface roughness. The high surface scattering coefficient will cause the system to produce stray light, which decreases the reflectivity of $\mathrm{SiC}$ mirrors and consequently results in the degradation of imaging quality of optical system [2]. Thus, improving machined surface quality of $\mathrm{SiC}$ is critical for facilitating the performance of $\mathrm{SiC}$ mirrors.

At present, annular polishing technology is an efficient method to obtain $\mathrm{SiC}$ mirrors with high surface quality [3-6]. Some typical work are as follows: Rupp et al. studied the grinding and polishing of conventional optics and found that the contact pressure between the specimen and the polishing pad changes dynamically, and is a function of time and location of points on the specimen [2]. Aspden et al. developed a CNC surface polisher that uses a small tool to achieve the desired profile by convolution to calculate the dwell time of the widget. In their topics, there is no single mathematical model that completely correlates the mechanical motion of optical surfaces with the amount of material removed during grinding or polishing process [7]. Wagner and Shannon established a model to describe the relationship between the mechanical motion and the change in surface area and to calculate the material removal of the specimen surface through the mathematical method and optical kinematics principle [8]. Gao and Cao studied the relationship between motion parameters, grinding mechanism, and the trajectory of the specimen [9]. Shen and Yuan studied the influence of applied load on pressure profile in the polishing process [10]. Liu et al. introduced the use of annular polishing technology for the manufacturing of large-diameter square optical components [11]. On the other side, the annular polishing is strongly dependent on polishing conditions. Wang et al. found that as the pressure 
increases, the contact area between the polishing pad and the workpiece increases, while the mechanical friction is enhanced and the material removal rate is high. As the rotation speed increases, the thickness of the polishing liquid film between the polishing pad and the workpiece gradually increases, the flow rate of the polishing liquid increases, leading to increased materials taken away from the processed surface under an increased material removal rate [12]. Sun et al. found that the oxidant, the complex agent content, and the polishing solution $\mathrm{PH}$ value in the polishing solution have a great influence on the material removal rate [13]. $\mathrm{Hu}$ et al. studied the effects of abrasive types such as $\mathrm{SiO}_{2}, \mathrm{Al}_{2} \mathrm{O}_{3}$, and $\mathrm{CeO}$, the concentration of abrasives and the size of abrasive grains on the polishing effect [14]. More recently, Zhang et al. performed finite element simulations and experiments of annular polishing of $\mathrm{SiC}$ and found that the distribution of contact pressure on the $\mathrm{SiC}$ specimen is significantly affected by the polishing speed, Poisson's ratio, and the elastic modulus of polishing pad [15].

Previous studies have obtained many valuable insights. However, most of previous work is mainly utilizing a sole method, either experiment or simulation. In particular, the lack of systematic experimental demonstration of theoretical analysis greatly restricts the deep understanding of the annular polishing mechanism of SiC. Therefore, based on the Preston equation and motion simulation, this paper analyzes the law of motion coupling in annular polishing and summarizes the polishing parameters that affect the annular polishing. Based on the analytical theoretical investigations, annular polishing experiments are carried out to further study the influence of different polishing parameters and ultimately obtain the optimized polishing parameters. This research has important theoretical significance and practical value to guide the annular polishing processing of $\mathrm{SiC}$.

\section{Analytical Investigation of Annular Polishing}

2.1. Kinematic Coupling of Motions. Figure 1(a) illustrates a typical annular polisher, which mainly consists of a polishing disc, a carrier disc, and a swinging bracket, respectively. The specimen is pasted on the carrier disc with paraffin, which means that the specimen has a synchronous speed with the carrier disc. The applied pressure is provided by the weight of carrier disc. Accordingly, Figure 1(b) illustrates the simplified motion diagram in the annular polishing, which indicates that the kinematic coupling of relative motions mainly includes the rotation of polishing disc and the rotation of carrier disc. As indicated in Figure 1(b), the speed of carrier disc is $\omega$ and the speed of polishing disc is $\delta$. The distance from the center of specimen $\mathrm{O}_{2}$ to a point $\mathrm{A}$ on the carrier disc is $r$, and the distance from the center of polishing disc $\mathrm{O}_{1}$ to the center of the carrier disc $\mathrm{O}_{2}$ is $R$. The angle between the line segments $\mathrm{AO}_{2}$ and $\mathrm{O}_{1} \mathrm{O}_{2}$ is $\theta$. The speed at the point $A$ on the polishing disc relative to $\mathrm{O}_{1}$ is $V_{1}$, and the speed at the point $\mathrm{A}$ on the specimen relative to $\mathrm{O}_{2}$ is $V_{2}$, so the relative speed of the specimen and the polishing disc at point $\mathrm{A}$ is $V$, which can be derived from the following equation [16].

$$
V(r, \theta)=\left[R^{2} \delta^{2}+r^{2}(\delta-\omega)^{2}+2 r R \delta(\delta-\omega) \cos \theta\right]^{1 / 2} .
$$

2.2. Preston Equation. Both material removal rate and surface quality of specimen in the annular polishing process are strongly affected by processing polishing parameters, which have complex interactions. Preston et al. simplified the Preston equation [17] to characterize the relationship between material removal and polishing speed V, applied pressure $\mathrm{P}$, and other external factors, as shown in the following equation [17]:

$$
\frac{d h}{d t}=k P V=k P \frac{d s}{d t},
$$

where $h$ is the amount of material removal and $k$ is a proportional constant that is related to various environmental factors. Therefore, the amount of material removal at one specific point can be derived according to Equation (2). However, the contact between specimen and polishing disc changes dynamically with polishing time, which induces uncertainties in the analytical investigation of annular polishing process. Therefore, three main assumptions are made to simplify the operation: (1) specimen and polishing disc are fully contacted without separation; (2) the applied pressure does not change with polishing time; and (3) the proportional constant $k$ does not change with polishing time. According to the Preston equation, the amount of material removal within a specific polishing time can be derived by integrating over time $t$, as shown in the following equation:

$$
h(r)=k \int_{0}^{T} P(r, t) \cdot V(r, t) d t .
$$

It can be seen from Equation (3) that the material removal is only dependent on the resultant speed $V$, given the $k$ and the $P$ are constant values. By substituting the relative velocity derived from Equation (1) into Equation (3), the material removal at point $A$ can be derived, as shown in the following equation [15]:

$$
\begin{aligned}
h(r)= & k \int_{0}^{T} P(r, t) \\
\cdot & {\left[R^{2} \delta^{2}+r^{2}(\delta-\omega)^{2}+2 r R \delta(\delta-\omega) \cos \theta\right]^{1 / 2} d t . }
\end{aligned}
$$

The amount of material removal at any point on the specimen can be calculated from Equation (4). The pressure $P$ is affected by the type of polishing pad and polishing solution. Based on the annular polishing motion simulation and the Preston equation, four influential parameters can be determined: as polishing solution, polishing pad, polishing time, and rotation speed of polishing disc, respectively.

\section{Annular Polishing Experiment of RB-SiC}

3.1. Effect of Polishing Solution Material. It has been demonstrated that polishing solution's particle size, particle hardness, and concentration have a strong impact on the 


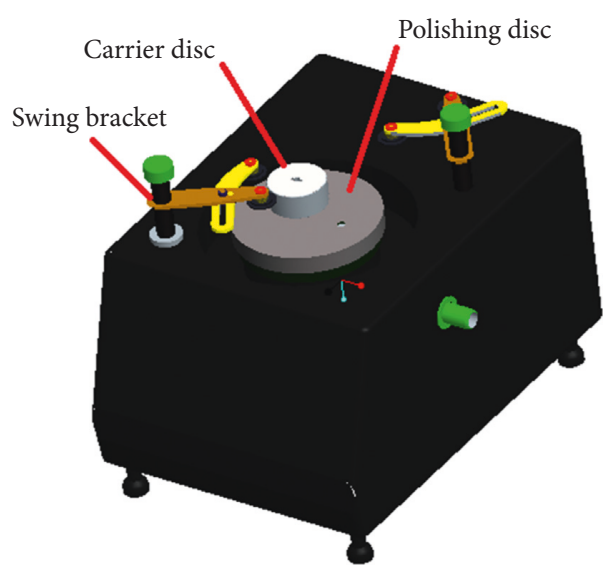

(a)

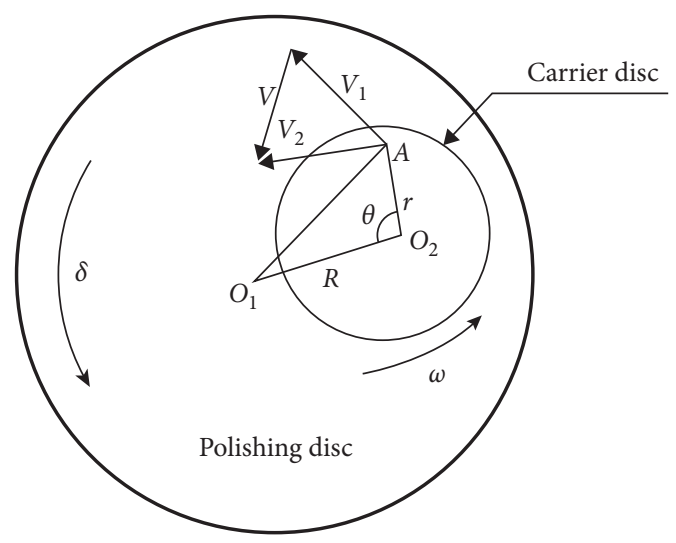

(b)

FIGURE 1: Illustration of annular polishing. (a) Model of annular polisher; (b) motion analysis of annular polishing. Reproduced from Zhang et al. [15] (under the Creative Commons Attribution License/public domain).

polishing process [18]. We first investigate the influence of polishing solution material on the polishing results. Three kinds of polishing solution materials such as alumina, silica, and diamond are considered. For each polishing solution material, the average particle size is the same as $250 \mathrm{~nm}$. In the polishing experiments, the polyurethane polishing pad is used with a rotation speed of $120 \mathrm{r} / \mathrm{min}$. The polishing time is $60 \mathrm{~min}$. After polishing, the surface roughness of the specimen is measured by a Taylor Hobson surface profiler.

Figure 2 presents the value of surface roughness for each polishing solution material. The surface roughness is the maximum of $7.3 \mathrm{~nm}$ for the alumina, followed by $6.1 \mathrm{~nm}$ for the silica, and the minimum of $3.2 \mathrm{~nm}$ for the diamond. It can be seen from Figure 2 that with the increase of abrasive hardness of the polishing solution, the surface roughness of the specimen decreases gradually, as the increase of abrasive hardness results in an improvement not only in the mechanical force between the specimen and abrasive but also in the quality of the specimen surface.

3.2. Effect of Polishing Pad Material. The polishing pad should has the following conditions: appropriate rigidity and hardness, a certain elasticity, good retention of the polishing solution, excluding the by-product of polishing process, and low impurities of the polishing pad [19]. In this paper, we use four kinds of polishing pad materials: the cot polishing pad, the matte leather polishing pad, the synthetic leather polishing pad, and the polyurethane polishing pad.

In different polishing experiments with different polishing pad materials, all the polishing parameters are kept constant. And the diamond suspension solution is used as the polishing solution for each experiment. The speed of polishing plate is $120 \mathrm{r} / \mathrm{min}$, and the polishing time is $60 \mathrm{~min}$. After the polishing experiment, the measured surface roughness of $\mathrm{SiC}$ is $7.6 \mathrm{~nm}, 6.9 \mathrm{~nm}, 8.1 \mathrm{~nm}$, and $2.8 \mathrm{~nm}$ for the cot polishing pad, the matte leather polishing pad, the synthetic leather polishing pad, and the polyurethane polishing pad, respectively, as shown in Figure 3.

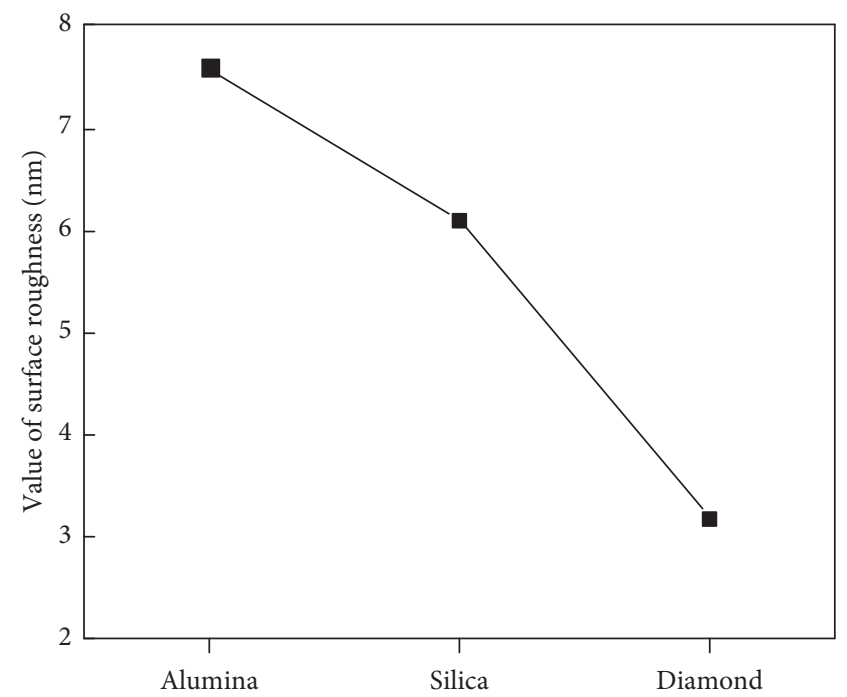

FIGURE 2: The relationship between the surface roughness and the type of polishing solution.

It can be seen from Figure 3 that surface roughness drops to the smallest value when using the polyurethane polishing pad. It can be concluded that due to the higher hardness of $\mathrm{SiC}$ specimen than the cot polishing pad, abrasive particles are pressed into the polishing pad, and thus are unable to produce effective force on the $\mathrm{SiC}$ surface, resulting in low processing precision and high surface roughness. The hardness of matte leather and synthetic leather polishing pad is higher, but the surface is easier to be scratched as a result of the higher interaction force, which results in higher surface roughness. The hardness of polyurethane polishing pad is moderate, which can obtain the best polishing effect with the lowest surface roughness of $2.8 \mathrm{~nm}$.

3.3. Effect of Polishing Time. We further investigate the influence of polishing time on the machined surface quality of SiC. While maintaining the other polishing parameters 


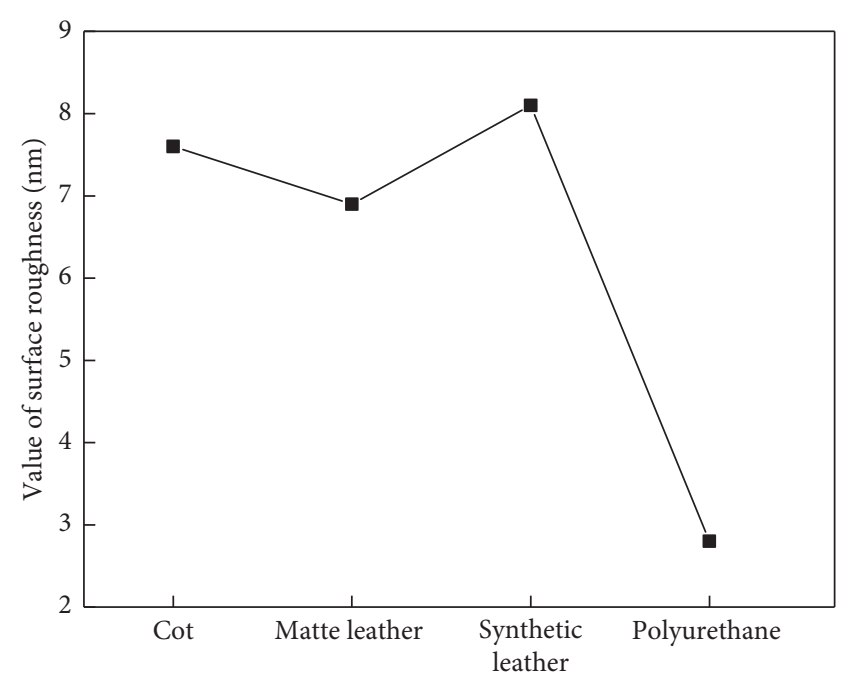

FIGURE 3: The relationship between the surface roughness and the type of polishing pad.

unchanged, only the polishing time is changed. The polishing time is divided into six groups: $30 \mathrm{~min}, 60 \mathrm{~min}$, $90 \mathrm{~min}, 120 \mathrm{~min}, 150 \mathrm{~min}$, and $180 \mathrm{~min}$, respectively. In each experiment, the diamond suspension is used as the polishing solution, and the polyurethane polishing pad is utilized. The polishing pad speed is $120 \mathrm{r} / \mathrm{min}$. After the polishing, the measured surface roughness is $3.2 \mathrm{~nm}, 2.5 \mathrm{~nm}, 2.1 \mathrm{~nm}$, $1.6 \mathrm{~nm}, 0.8 \mathrm{~nm}$, and $1.2 \mathrm{~nm}$ for the polishing time of $30 \mathrm{~min}$, $60 \mathrm{~min}, 90 \mathrm{~min}, 120 \mathrm{~min}, 150 \mathrm{~min}$, and $180 \mathrm{~min}$, respectively, as shown in Figure 4.

It can be seen from Figure 4 that the surface roughness changes with the polishing time: it first decreases steadily and then starts to increase from the polishing time of $150 \mathrm{~min}$, indicating a critical polishing time of $150 \mathrm{~min}$. In the initial stage of the polishing experiment, large abrasive particles are embedded into the surface to accommodate large pressure, which leads to generation of surface scratches, thus affecting the surface quality. With the increase of polishing time, abrasive particles break up to small particles with sharp edges that have good cutting performance, which facilitates the formation of smooth surface of the specimen. The surface roughness reaches the lowest value of $0.8 \mathrm{~nm}$ at the polishing time of 150 minutes. However, with the further increase of polishing time, the increase of surface temperature produces thermal stress, which affects the machining accuracy and lowers the surface roughness.

3.4. Effect of Rotation Speed of Polishing Disc. We also investigate the influence of rotation speed of polishing disc. Six rotation speeds of polishing disc are considered: $50 \mathrm{r} / \mathrm{min}$, $70 \mathrm{r} / \mathrm{min}, 90 \mathrm{r} / \mathrm{min}, 120 \mathrm{r} / \mathrm{min}, 140 \mathrm{r} / \mathrm{min}$, and $160 \mathrm{r} / \mathrm{min}$, respectively. For each rotation speed, all the other polishing parameters are the same. The diamond suspension is used as the polishing solution, and the polyurethane polishing pad is utilized. The polishing time is $60 \mathrm{~min}$. After the polishing experiment, the measured surface roughness is

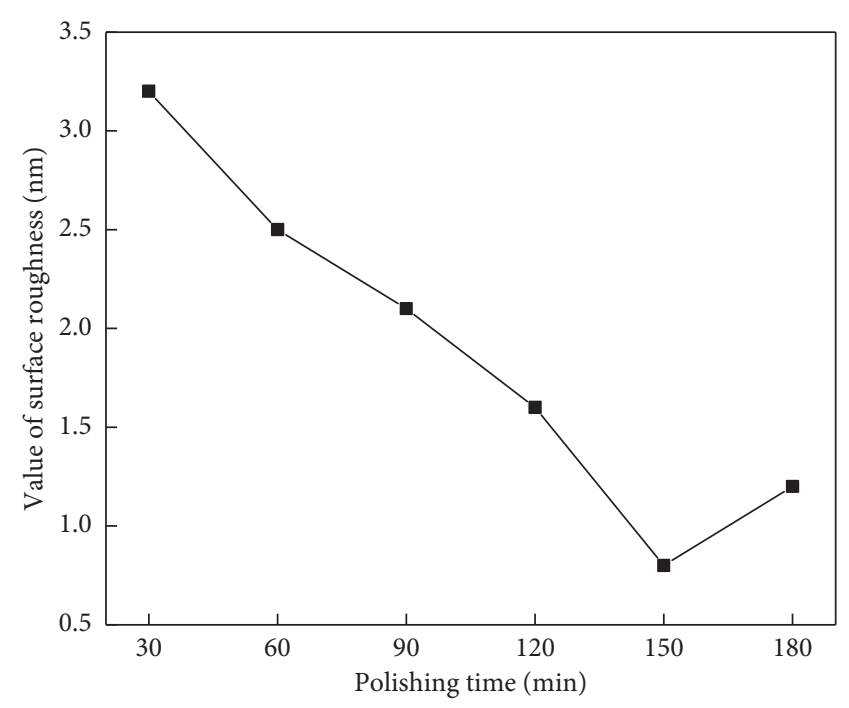

FIGURE 4: The relationship between the surface roughness and the polishing time.

$3.3 \mathrm{~nm}, 2.7 \mathrm{~nm}, 2.5 \mathrm{~nm}, 1.6 \mathrm{~nm}, 1.2 \mathrm{~nm}$, and $2.6 \mathrm{~nm}$ for the rotation speed of $50 \mathrm{r} / \mathrm{min}, 70 \mathrm{r} / \mathrm{min}, 90 \mathrm{r} / \mathrm{min}, 120 \mathrm{r} / \mathrm{min}$, $140 \mathrm{r} / \mathrm{min}$, and $160 \mathrm{r} / \mathrm{min}$, respectively, as shown in Figure 5.

It can be seen from Figure 5 that with increasing rotation speed, the surface roughness first decreases and reaches the lowest value of $1.2 \mathrm{~nm}$ at the rotation speed of $140 \mathrm{r} / \mathrm{min}$ and then increases with a further increase of rotation speed. It is known that a high rotation speed of the polishing disk can increase the efficiency of the polishing process. However, the higher the rotation speed of polishing disc, the lower the processing stability, which result in the lower surface formation accuracy.

Based on the above analysis, the optimized parameters of annular polishing of $\mathrm{SiC}$ are summarized as follows: a rotating speed of polishing disc is $140 \mathrm{r} / \mathrm{min}$, a polishing time is $150 \mathrm{~min}$, using the polyurethane polishing pad and the diamond suspension solution. Under the optimized polishing conditions, a high-quality $\mathrm{SiC}$ specimen with a surface roughness of $1.31 \mathrm{~nm}$ is obtained. Figure 6 shows the characterized $\mathrm{SiC}$ specimen before and after polishing, indicating polished $\mathrm{SiC}$ with good surface quality can be obtained by using the optimized annular polishing parameters.

\section{Summary}

In this work, we experimentally investigate the optimization of annular polishing parameters of RB-SiC by first analytical investigation of influential parameters based on the Preston equation and the coupling of polishing motions, and then systematic polishing experiments and characterization. It is found that the annular polishing process can be greatly influenced by the polishing solution: the polishing pad material, the polishing time, and the rotation speed of polishing disc. The optimized annular polishing parameters are a rotating speed of polishing disc of $140 \mathrm{r} / \mathrm{min}$, a polishing time of $150 \mathrm{~min}$, using polyurethane polishing pad 


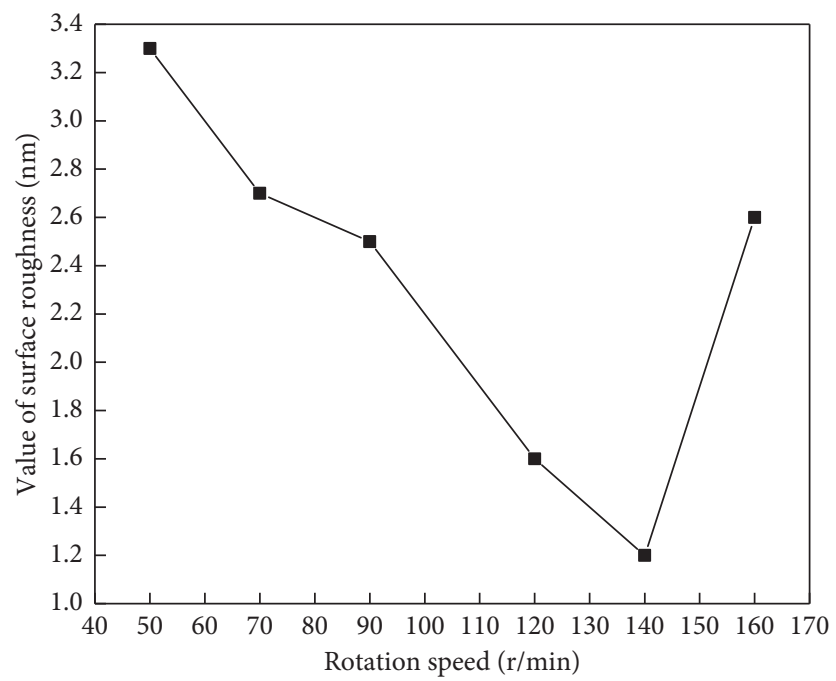

Figure 5: The relationship between the surface roughness and the rotation speed.

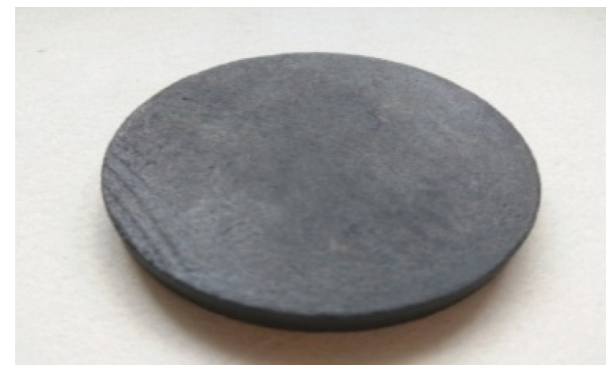

(a)

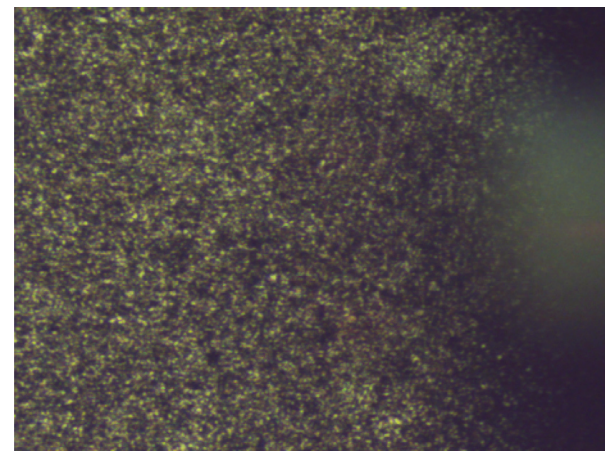

(c)

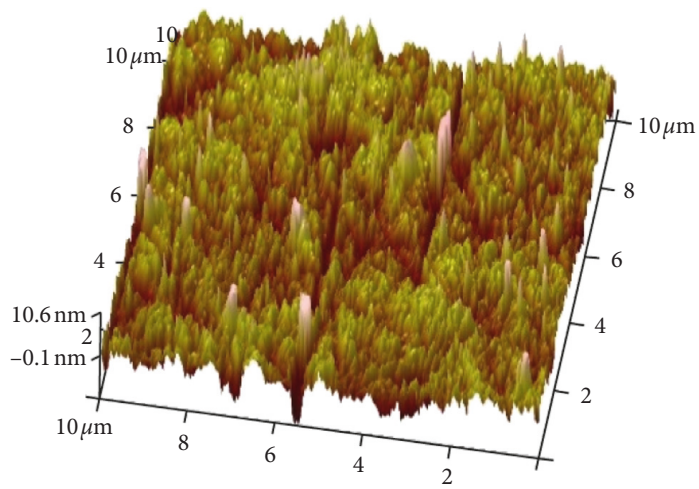

(e)

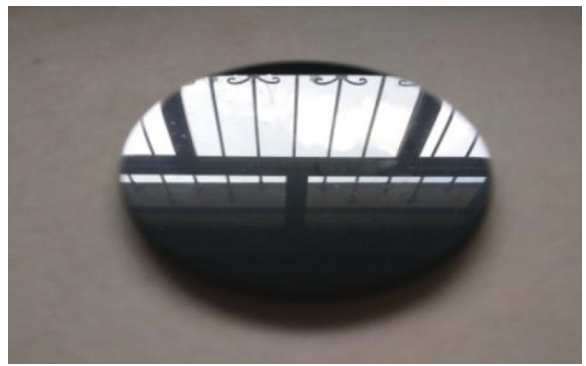

(b)

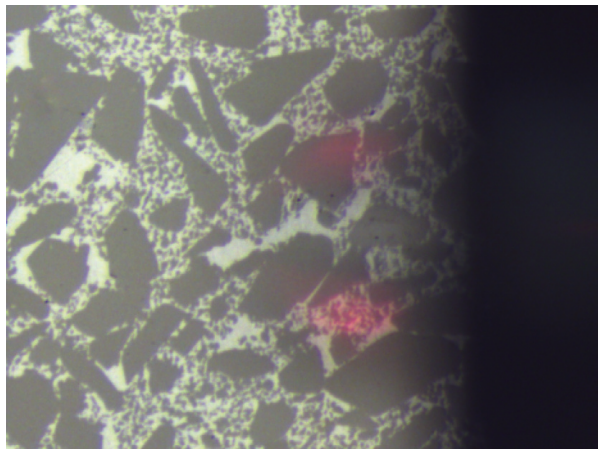

(d)

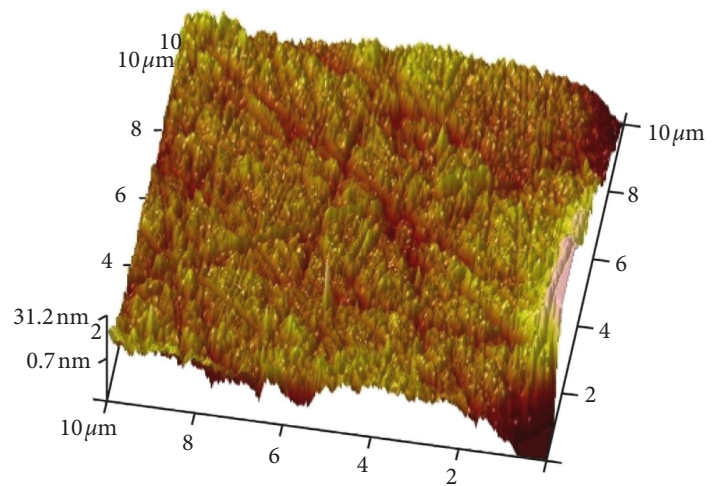

(f)

FIGURE 6: Morphology and microstructure of polished SiC. (a) Before polishing, (b) after polishing, (c) surface morphology before polishing, (d) surface morphology after polishing, (e) surface microstructure before polishing, and (f) surface microstructure after polishing. 
and diamond suspension solution, which lead to a surface roughness of $1.31 \mathrm{~nm}$ of $\mathrm{RB}-\mathrm{SiC}$ by annular polishing.

\section{Data Availability}

The data used to support the findings of this study are included within the article.

\section{Conflicts of Interest}

The authors declare that they have no conflicts of interest.

\section{Authors' Contributions}

Y. L., H. L., and J. Z. conceived and designed the experiments; L. H. and Y. S. performed the analytical investigation and experiments; Y. L. and J. Z. analyzed the data and wrote the paper.

\section{Acknowledgments}

The authors acknowledge financial support from the $\mathrm{Na}$ tional Natural Science Foundation of China (NSFC) (51875119 and 61473096), the Fundamental Research Funds for the Central Universities, the German Research Foundation (DFG) International Joint Research Program (51761135106), and the National Key R\&D Program of China (2016YFB0501203).

\section{References}

[1] R. Joseph, S. Jay, and L. David, "Recent advances in reaction bonded silicon carbide optics and optical systems," Proceeding of SPIE, vol. 5868, article 586802, 2005.

[2] V. Rupp, "The development of optical surfaces during the grinding process," Applied Optics, vol. 4, no. 6, pp. 743-748, 1965.

[3] F. Gritti and G. Guiochon, "Gradient chromatography under constant frictional heat: Realization and application," Journal of Chromatography A, vol. 1289, pp. 1-12, 2013.

[4] X. C. Wang, C. C. Wang, X. T. Shen, and F. H. Sun, "Potential material for fabricating optical mirrors: polished diamond coated silicon carbide," Applied Optics, vol. 56, no. 14, pp. 4113-4122, 2017.

[5] Q. T. Fan, J. Q. Zhu, and B. A. Zhang, "Effect of the geometry of workpiece on polishing velocity in free annular polishing," Chinese Optics Letters, vol. 5, pp. 298-300, 2007.

[6] Y. Hashimoto, S. Oshika, N. Suzuki, and E. Shamoto, "A new contact model of pad surface asperities utilizing measured geometrical features," in Proceedings of the International Conference on Planarization/CMP Technology, pp. 1-4, Chandler, AZ, USA, September-October 2015.

[7] R. Aspden, R. Mcdonough, and F. R. Nitchie, "Computer assisted optical surfacing," Applied Optics, vol. 11, no. 12, pp. 2739-2747, 1972.

[8] R. E. Wagner and R. R. Shannon, "Fabrication of aspherics using a mathematical model for material removal," Applied Optics, vol. 13, no. 7, pp. 1683-1689, 1974.

[9] H. G. Gao and J. L. Cao, "Simulation of stock removal uniformity during eccentric plane polishing by a tin lap," Chinese Journal of Scientific Instrument, vol. 21, pp. 83-85, 2000.
[10] Z. W. Shen and J. L. Yuan, "Ultra-precision planarization for crystals," Journal of Zhejiang University-Technology, vol. 29, pp. 20-25, 2001.

[11] M. C. Liu, X. Y. Hu, and Z. S. Li, "Research of fabricating large quadrate high-precision plane optical elments," Optics Technology, vol. 27, pp. 518-519, 2004.

[12] B. L. Wang, H. Gao, X. J. Teng, and R. K. Kang, "Effect of polishing parameter on material removal and surface quality of KDP crystal," Journal of Synthetic Crystals, vol. 39, pp. 29-33, 2010.

[13] J. Z. Sun, G. S. Pan, Y. H. Zhu, Y. J. Dai, J. B. Luo, and W. M. Li, "Influence of slurry ingredients as particle on hard disk substrate polishing," in Advanced Tribology, J. Luo, Y. Meng, T. Shao, and Q. Zhao, Eds., pp. 993-994, Springer, Berlin, Heidelberg, 2007.

[14] W. Hu, X. Wei, X. Z. Xie, and B. P. Xiang, "Study on the performance of polishing slurry in chemical mechanical polishing," Diamond and Abrasives Engineering, vol. 156, pp. 78-80, 2006.

[15] J. J. Zhang, L. Han, H. Y. Liu, Y. K. Shi, Y. D. Yan, and T. Sun, "Theoretical and experimental studies of over-polishing of silicon carbide in annular polishing," Machines, vol. 6, no. 2, p. 15, 2018.

[16] R. L. Goedecke and R. M. Jackson, "A fractal expansion of a three dimensional elastic-plastic multi-scale rough surface contact model," Tribology International, vol. 59, pp. 230-239, 2013.

[17] F. Preston, "The theory and design of plate glass polishing machines," Journal of the Society of Glass Technology, vol. 11, pp. 214-256, 1927.

[18] Y. D. Filatov, A. G. Vetrov, and V. I. Sidorko, "Polishing of optoelectronic components made of monocrystalline silicon carbide," Journal of Superhard Materials, vol. 37, no. 1, pp. 48-56, 2015.

[19] D. Liu, G. Chen, and Q. Hu, "Material removal model of chemical mechanical polishing for fused silica using soft nanoparticles," International Journal of Advanced Manufacturing Technology, vol. 88, no. 9-12, pp. 3215-3525, 2016. 


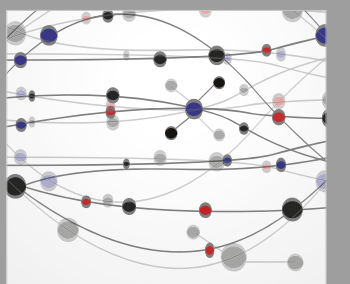

The Scientific World Journal
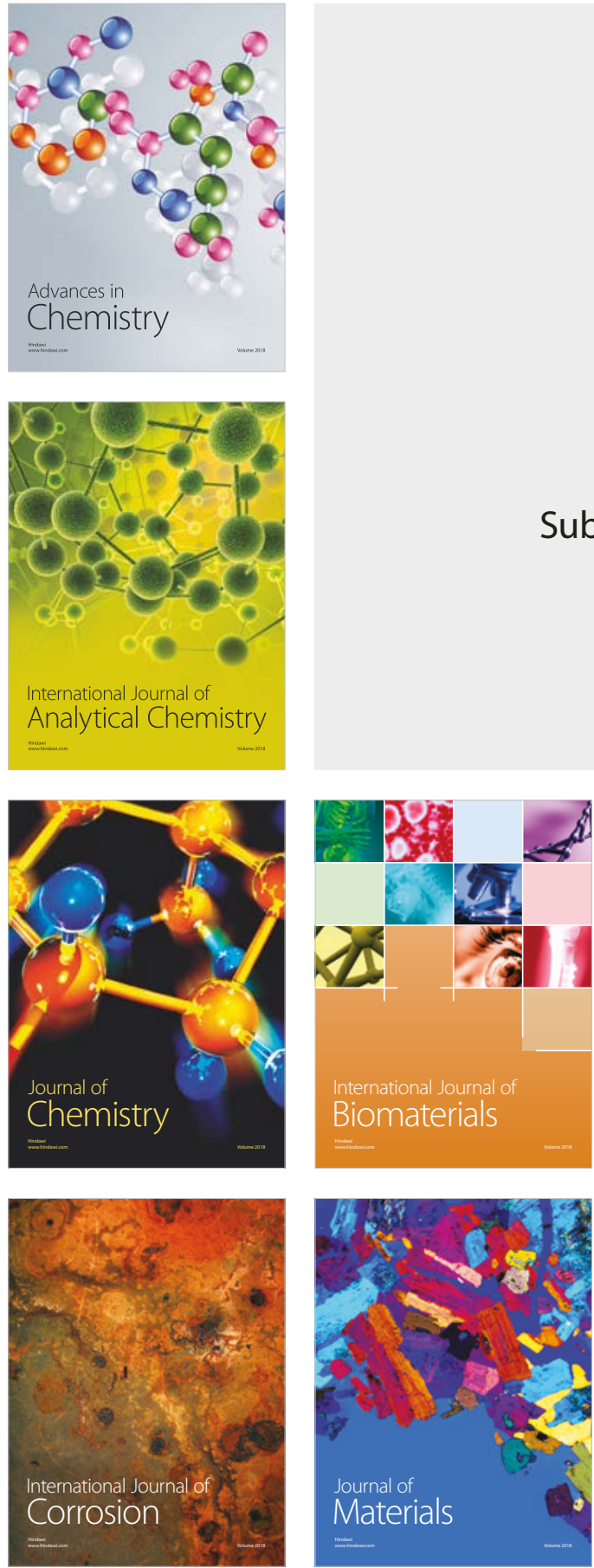

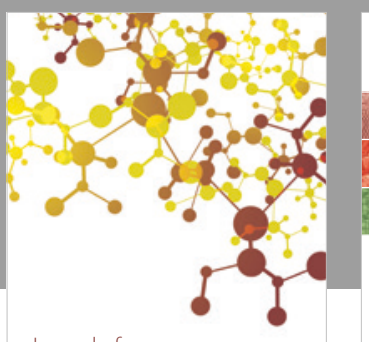

Journal of

Applied Chemistry
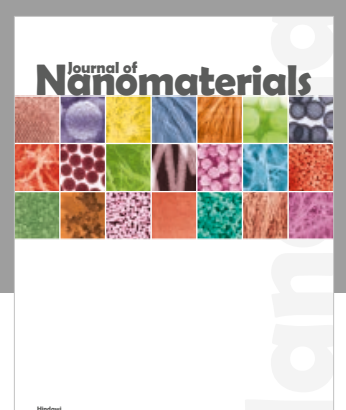

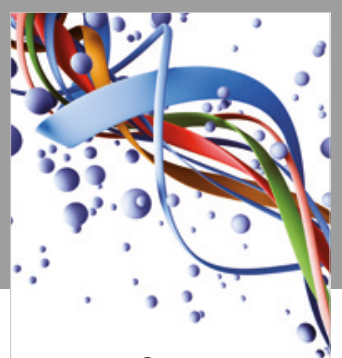

Scientifica

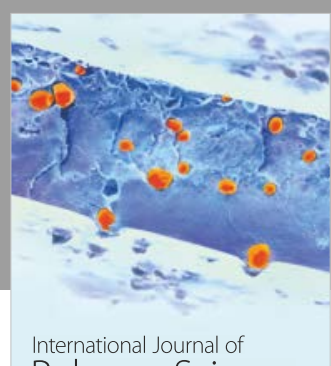

Polymer Science

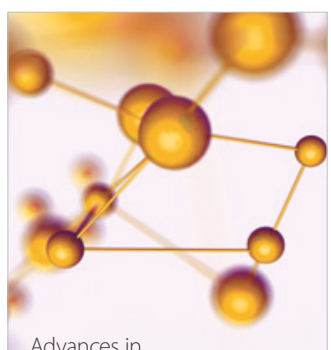

Physical Chemistry
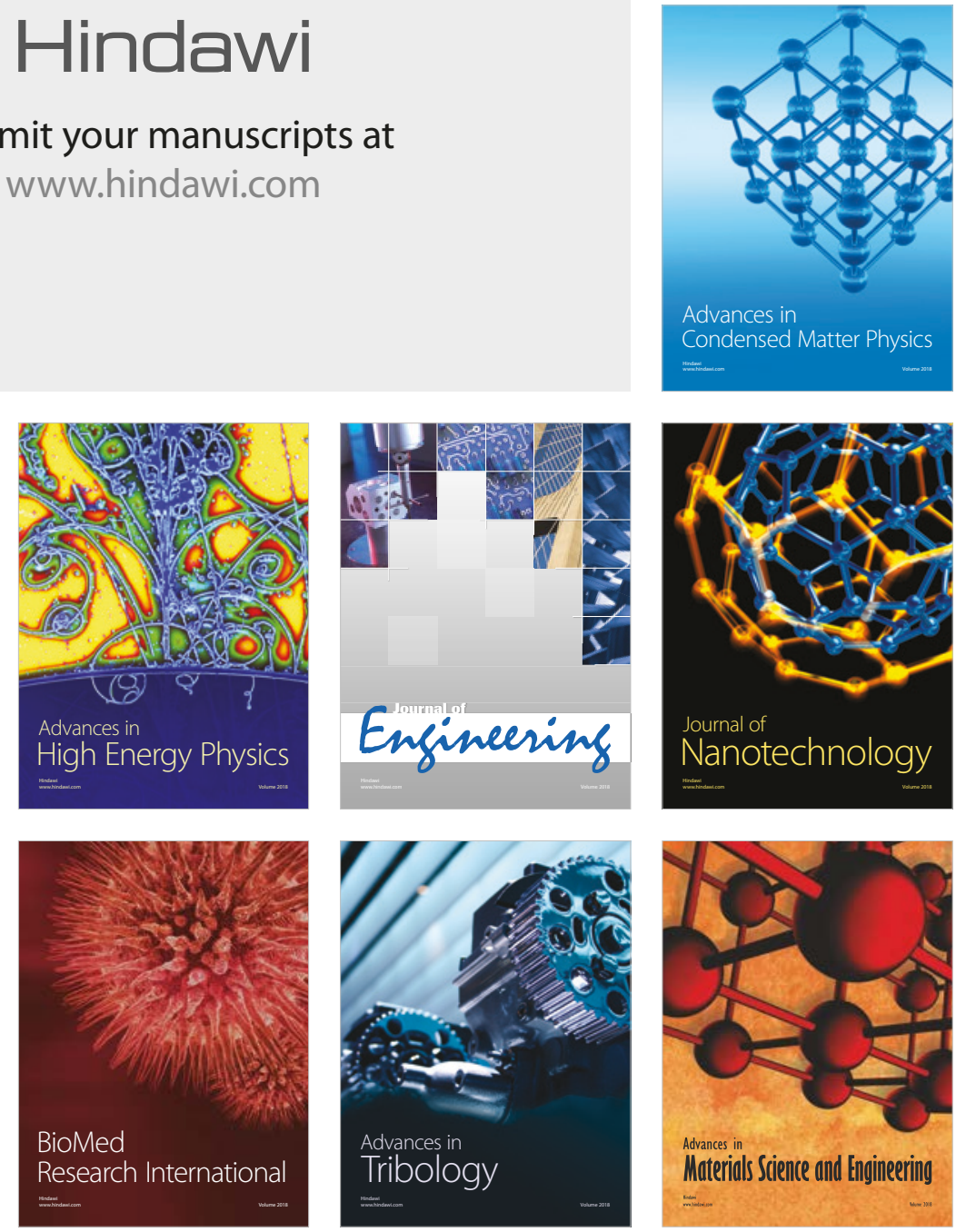